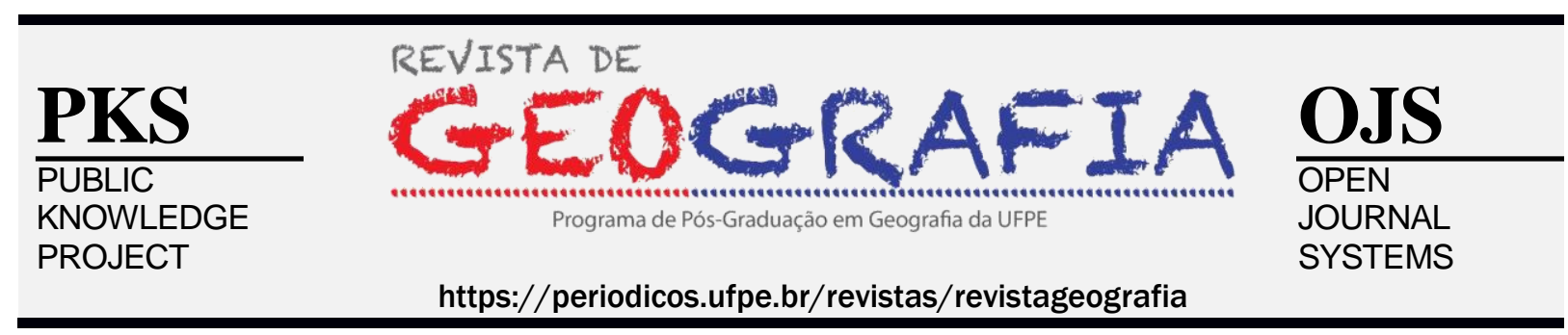

\title{
GEOGRAFIA E TRABALHO DE CAMPO: OLHARES E PERSPECTIVAS A PARTIR DA ABORDAGEM ETNOGEOGRÁFICA
}

\author{
David Tavares Barbosa ${ }^{1}$ \\ ${ }^{1}$ Doutorando em Geografia na Universidade Federal do Rio de Janeiro. E-mail: davidtgeo@gmail.com
}

Artigo recebido em 08/11/18 e aceito em 12/05/19

\begin{abstract}
RESUMO
No presente artigo, buscaremos apresentar uma análise crítica sobre o status do trabalho de campo para a disciplina geográfica contemporânea. Para tal, adotaremos alguns aportes teórico-metodológicos fornecidos por abordagens da geografia que dialogam com a perspectiva etnográfica do trabalho de campo. A partir dessa abordagem, buscaremos destacar o caráter comunicativo, crítico e situacional do campo, que envolve um conjunto de interações culturais, práticas discursivas e espaciais entre o pesquisador, os grupos sociais estudados e a produção efetiva dos dados.
\end{abstract}

Palavras-chave: Trabalho de campo; Etnogeografia; Geografia Cultural.

\section{GEOGRAPHY AND FIELDWORK: VIEWS AND PERSPECTIVES FROM THE ETHNOGEOGRAPHIC APPROACH}

\begin{abstract}
In this article, we will present a critical analysis of the status of the fieldwork for the contemporary geographical studies. For this, we will adopt some theoretical-methodological contributions provided by geography approaches that dialogue with the ethnographic perspective of fieldwork. From this approach, we will seek to highlight the communicative, critical and situational character of the field, which involves a set of cultural interactions, discursive and spatial practices between the researcher, the social groups studied and the effective production of the data.
\end{abstract}

Keywords: Fieldwork; Etnogeography; Cultural Geography. 


\section{INTRODUÇÃO}

Geógrafos de diferentes abordagens asseguram a centralidade do trabalho de campo para a constituição e desenvolvimento da Geografia. Conforme destaca Paul Claval, a própria concepção da disciplina, a partir do final do século XVIII, articula-se à validade científica adquirida pelo trabalho de campo no contexto científico: a partir da influência da corrente filosófica do nominalismo, o campo se institui na disciplina como prova da verdade científica, de valorização da experiência, garantia de autenticidade e fundamento pessoal da verdade (CLAVAL, 2013, p. 01-03). Em abordagem correlata, Do Rio (2011) destaca que essa compreensão atribuiu ao trabalho de campo a função primeira de construção dos dados objetivos da pesquisa, enquanto meio de coleta de dados que envolve o pesquisador de forma direta no contato com o mundo. O campo, enquanto fragmento da realidade disponível para apreensão, permitiria um contraste com as hipóteses, via observação visual e suposição de correspondência direta entre o visto no terreno e o conhecimento da realidade (KATZ, 2009; ZUSMAN, 2011).

Entretanto, há que se considerar que tais características são componentes essenciais, não apenas da geografia, mas de parte importante do pensamento ocidental, no momento de constituição da ciência moderna, entre o fim do século XVI e início do século XVII. Outras disciplinas científicas também se desenvolveram a partir de tais questões: experiência direta do pesquisador, confronto permanente entre a ideia e o real, análise da organização das coisas, dentre outros (CLAVAL, 2013; PULMAN, 2007).

Contudo, apesar desse destacado papel da prática de campo na história da disciplina, esse procedimento tem se caracterizado na Geografia mais como um "imperativo moral"1 de reconhecimento profissional do que um procedimento reflexivo e fundamental da pesquisa científica. Geógrafos contemporâneos têm demonstrado uma quase generalizada abstenção na problematização do trabalho de campo, como se essa etapa da pesquisa fosse uma realidade física e evidente que foge à elaboração intelectual. Essa abstenção revela um problema metodológico e epistemológico: ainda que o campo seja um conceito teórico-prático, não deixa de ser um objeto conceitual, sendo necessário indagarmos sobre as consequências de

\footnotetext{
${ }^{1}$ A ideia de "imperativo moral" foi apresentada pelo sociólogo Stéphane Beaud e pela antropóloga Florence Weber para destacar a "moda" que transforma a pesquisa de campo como palavra-chave no discurso da mídia, da política e de diferentes categoriais profissionais, sem uma correspondente reflexão crítica e teórica sobre essa prática científica (BEAUD, WEBER, 2007). Paul Claval também menciona a existência de uma "mitologia do geógrafo" que sacraliza as práticas de trabalho de campo, atribuindo status e reconhecimento ao pesquisador e à pesquisa, independentemente de como este é feito (CLAVAL, 2013).

Barbosa, 2019 ISSN 0104-5490 
empregar este conceito à experiência que alguns afirmam ter do mundo (PULMAN, 2007; CLAVAL, 2013; DO RIO, 2011).

A partir dessa problemática, buscaremos apresentar neste artigo uma análise crítica sobre o atual status do trabalho de campo para a disciplina geográfica. Para tal, adotaremos alguns aportes teórico-metodológicos fornecidos por abordagens da geografia que dialogam com a perspectiva etnográfica do trabalho de campo (HERBERT, 2000; MACIEL, 2004, 2006; ALMEIDA, 2008; PATERSON, 2009; ZUSMAN, 2011; CLAVAL, 2013). A partir dessa abordagem, buscaremos destacar o trabalho de campo enquanto um recurso central à investigação geográfica, graças ao caráter comunicativo, crítico e situacional dessa prática, tanto para a história do pensamento geográfico, quanto para as pesquisas atuais.

\section{TRABALHO DE CAMPO NA GEOGRAFIA CONTEMPORÂNEA ${ }^{2}$}

Ao debater as características do campo para a ciência contemporânea, especialmente para a Antropologia e a Geologia, o sociólogo Bertrand Pulman destaca quatro questões que ele considera enquanto centrais para essa prática científica: a) o campo designa o objeto e o lugar onde se desenrola fisicamente o ato da pesquisa; ii) existência de algo da ordem do íntimo, da identidade própria do pesquisador, nas escolhas e observações realizadas durante o campo; iii) a prática do campo, ao mesmo tempo, valoriza as disciplinas (no caso, a Antropologia e a Geologia) e estabelece um discurso negativo sobre o passado dessas; iv) o campo é um lugar de confronto entre diferentes forças que se chocam no interior de uma cultura (PULMAN, 2007).

Na Geografia contemporânea, alguns trabalhos têm realizado reflexões semelhantes e analisado criticamente o papel dessa prática na história do pensamento e nas práticas atuais da disciplina. A partir de diferentes debates sobre o papel do campo para a pesquisa qualitativa, assim como suas conexões diretas com a condução reflexiva do processo de investigação, gostaríamos de destacar dois debates observados na atualidade que colocam novas questões à disciplina: as críticas contemporâneas à prática de campo observada na Geografia Tradicional; os novos paradigmas epistemológicos da ciência e seus possíveis direcionamentos à novas práticas e posturas do geógrafo.

\footnotetext{
2 Agradeço aos diálogos estabelecidos com a professora Ana Maria Lima Daou e companheiros de turma da disciplina "Tópicos especiais em Geografia Humana - Pesquisa Qualitativa" realizada no segundo semestre de 2015, no âmbito do Programa de Pós-Graduação em Geografia da UFRJ, onde foram debatidas algumas das questões e bibliografias aqui apresentadas. 
De início, percebe-se que as críticas ao campo da Geografia Tradicional se fazem via diferentes apreciações: leituras críticas ao predomínio das metodologias visuais na prática de campo (KATZ, 2009; CLAVAL, 2013); questionamento à exclusão dos geógrafos de seus espaços de estudo, em nome da perspectiva científica e objetiva da ciência (BAITZ, 2006; HERBERT, 2000; PATERSON, 2009; CLAVAL, 2013); oposições ao exagerado empirismo na disciplina, que ignora o debate entre métodos e teoria, pensando o campo apenas como verificação da realidade (ALENTEJANO e ROCHA-LEÃO, 2006; TRICART, 2006; DO RIO, 2011); ou ainda, questionamentos acerca da dicotomia Geografia Física/Geografia Humana e seus reflexos nos caminhos escolhidos para a pesquisa de campo, criando uma fragmentação da percepção da realidade (ALENTEJANO e ROCHA-LEÃO, 2006).

Cientes dessa diversidade de apontamentos críticos, gostaríamos de iniciar nossas análises a partir do debate sobre a necessidade de superação da contraposição entre os dados observacionais e conhecimentos teóricos, presentes na concepção das práticas de campo desde a geografia tradicional. Conforme destacam Paterson (2009) e Claval (2013), essa objetividade da relação do pesquisador com o campo encontra-se vinculado ao predomínio de uma espécie de regime óptico do conhecimento, de caráter hierárquico e vertical, que distancia o olhar geográfico das experiências cotidianas.

Algumas abordagens da Geografia contemporânea destacam a necessidade de superar tal objetividade da visão a partir de uma abordagem háptica, de um reconhecimento da experiência encarnada, tátil, corpórea, não apenas visual, do pesquisador, também um sujeito ativo na produção dos dados em campo (PATERSON, 2009; CLAVAL, 2013). A contraposição à perspectiva puramente visual da ciência e das práticas de campo se apresenta como uma das principais posturas epistemológicas de algumas abordagens culturais da Geografia.

Convém destacar um exemplo dessas abordagens renovadas. Augustin Berque, "geógrafo orientalista" e influente estudioso do campo nomeado por alguns como "geografia cultural-humanista", tem buscado destacar que no estudo da territorialidade humana, o que está de fato em causa não é somente a visão, mas todos os sentidos, todos os modos de relação dos indivíduos com o mundo (BERQUE, 2012, p. 241). Para este autor, nossas relações com o mundo se estabelecem a partir de relações histórica e culturalmente dadas, guiadas pelos diferentes sentidos que as sociedades humanas dão aos seus ambientes.

Em tal ponto, precisamos esclarecer que este autor não almeja negar a perspectiva visual de nossas experiências, mas apenas considerar uma abordagem do mundo para além 
dessa predominância ocular. O contraponto se estabelece à "coisificação" consciente do processo dinâmico e interativo da observação das paisagens, que reduz o senso das coisas ao olhar e esquece toda a complexidade socioespacial e cultural desses contatos com o mundo. Pensamos que as reflexões desse autor se ligam de modo direto às questões aqui consideradas sobre o trabalho de campo.

Retomando, dentro desse conjunto de críticas, há também alguns novos paradigmas da ciência que tem possibilitado a renovação dos contextos e procedimentos da pesquisa de campo. Dentre diversos pontos focais dessa renovação, destacam-se a influência das geografias com abordagens feministas, o desenvolvimento de epistemologias críticas e pósmodernas, assim como o diálogo interdisciplinar com outras disciplinas (antropologia, em especial). Das geografias feministas, dois questionamentos são centrais: à pressuposição visual e dependência de 'pontos de vista' do trabalho de campo da Geografia clássica, tida como uma concepção que privilegia a objetividade e hierarquia das formas de observação (KATZ, 2009); a necessidade de valorizar a interlocução com os grupos não científicos, o empoderamento recíproco do pesquisador e dos pesquisados, bem como a preocupação de utilizar o campo como uma estratégia política de ativismo (CLAVAL, 2013).

Tal como as críticas feministas, Paul Claval também destaca o conjunto de críticas advindas das chamadas "epistemologias críticas" e "epistemologias do desejo", que se constroem em contraposição às "epistemologias da curiosidade"3 (CLAVAL, 2013). Segundo esse autor, tais abordagens estabelecem contrapontos à perspectiva visual do trabalho de campo e, em acréscimo, destacam a posicionalidade do conhecimento produzido nessa prática científica. Para tais leituras, o conhecimento sempre se produz de forma localizada e não universal, cuja atividade de campo, enquanto prática de produção de um conhecimento, se faz a partir da influência do ambiente social e político do pesquisador. Assim, as questões teóricometodológicas e práticas científicas devem ser consideradas em vínculo com os valores idiossincráticos e contextuais daquele que as produz.

Igualmente, Baitz (2006) destaca a contribuição de "métodos não-diretivos" no desenvolvimento de abordagens reflexivas de campo, que buscam problematizar a relação do pesquisador com a ciência. Segundo sua abordagem, na tentativa de romper a distância

\footnotetext{
${ }^{3}$ As chamadas "epistemologias críticas" e "epistemologias do desejo" que Paul Claval se refere correspondem às abordagens de tradição fenomenológica e pós-estruturalista desenvolvidas no mundo anglo-saxão e francês, a partir dos anos 1990. São abordagens que buscam estimular, dentre outras questões renovadas à abordagem do trabalho de campo, o engajamento intelectual, psicológico e pessoal dos pesquisadores. Para maiores informações sobre essas novas epistemologias e os autores relacionados ao seu debate, consultar o artigo, disponível em: https://journals.openedition.org/confins/8373. 
instituída entre pesquisador e objeto, a pesquisa implicada permitiria recuperar o pesquisador enquanto sujeito vivo e ativo no campo, reconhecendo assim que ciência e conhecimento não são neutros. Segundo sua abordagem, o pesquisador faz parte da pesquisa, sendo, no campo, mais um elemento do conjunto a analisar. Conforme reforçam Beaud e Weber (2007, p. 15), essa implicação do pesquisador em campo deve ser correlacionada a um comprometimento pessoal do pesquisador com a pesquisa, pois, em suas palavras:

[...] fazer pesquisa de campo é ter vontade de se agarrar aos fatos, de discutir com os pesquisados, de compreender melhor os indivíduos e os processos sociais. Sem essa sede de descobrir, sem essa vontade de saber, quase que de destrinchar, o campo torna-se uma formalidade, um exercício escolar, chato, sem interesse (BEAUD, WEBER, 2007, p. 15).

Essas abordagens renovadas sobre o trabalho de campo compreendem-no como algo mais que apenas uma etapa de pesquisa, concebendo-o como um modo de produção do conhecimento e uma forma de interpretação hermenêutica da prática científica. O campo revela-se como uma etapa científica situada na relação dinâmica entre lugares, processos e pessoas, dentre as quais, o próprio pesquisador (KATZ, 2009; BAITZ, 2006). Conforme destaca Katz (2009), trabalhar no campo não compreende apenas ir até um lugar qualquer, pois envolve a promoção de diálogos culturais, práticas discursivas e espaciais que podem influenciar diretamente nos resultados da pesquisa.

Nesse sentido, 'campo' e 'pesquisador' se apresentam enquanto co-construções de um conhecimento parcial, submetido às idiossincrasias do observador e às dinâmicas espaciais específicas desse encontro, sendo importante e necessário uma maior problematização sobre a questão. A partir desses apontamentos iniciais, buscaremos a seguir apresentar algumas possibilidades de construção do trabalho de campo etnogeográfico, visualizando o trabalho de campo como momento de encontro e vivência crítica frente à totalidade complexa e dialética do espaço geográfico.

\section{A ABORDAGEM ETNOGEOGRÁFICA DO TRABALHO DE CAMPO}

As abordagens e questões sobre o trabalho de campo apresentadas acima indicam algumas possibilidades de aproximação e de debate interdisciplinar com a Antropologia e seu trabalho de campo etnográfico. Há de se reconhecer que, tal como destacam Venturi (2006) e Lacoste (2006), problemas da pesquisa e do trabalho de campo não se colocam do mesmo modo para ambas as partes. Se para geógrafos o campo se revela quase sempre como uma técnica, para antropólogos o campo corresponde ao método utilizado de acordo com objetivos específicos (método etnográfico) (VENTURI, 2006; LACOSTE, 2006).

Barbosa, $2019 \quad$ ISSN 0104-5490 111


Igualmente, conforme apresenta Hoefle (2007), a convergência de interesses entre Geografia Cultural-Humana e Antropologia Cultural-Social se desenvolveu em detrimento da união interna das duas ciências. Herbert (2000) também aponta a presença de uma aversão à etnografia na geografia por três questões principais: a ideia que a etnografia não é científica, sendo excessivamente subjetiva; por sua preocupação com a questão subjetiva, é interpretado enquanto um conhecimento limitado para construir generalizações e teorias mais amplas; em suas análises existiriam poucas reflexões sobre suas práticas de representação inerentes.

Neste sentido, compreendemos os problemas da aproximação entre as duas estratégias de campo. Mas, a partir das questões (teóricas e empíricas) destacadas pelas abordagens culturais da Geografia contemporânea, observamos a possibilidade de estabelecer diálogos entre a abordagem geográfica e as questões antropológicas, via investigação das experiências do lugar e território, da construção de identidades e dos desígnios políticos presentes na mobilização dessas experiências pelos grupos sociais (CLAVAL, 2013). Assim, mais que uma espécie de diálogo com a antropologia e sua abordagem etnográfica, interessa-nos aproximar a Geografia do debate sobre a perspectiva 'etno' da ciência, assim como de suas possibilidades de aplicação aos estudos geográficos.

Para Claval $(1999 ; 2013)$ o radical etno tem possibilitado à ciência discutir a dimensão reflexiva da produção do conhecimento, bem como a compreensão da perspectiva do outro e a problematização dos métodos da ciência. Neste sentido, quando este autor propõe o termo "etnogeografia", no contexto de uma geografia de abordagem cultural, revela uma intenção de crítica à "lógica impessoal e objetiva do método científico habitual" (CLAVAL, 1999, p. 71) e um interesse de reconstituir a percepção que os homens têm do mundo. Essa aproximação com a perspectiva etnográfica permite que a geografia desenvolva novas reflexões sobre os processos e significados socioespaciais que motivam os grupos na construção e transformação de suas paisagens (HERBERT, 2000).

Paul Claval propõe três grandes questões que deveriam ser formuladas para compreender e desenvolver essa perspectiva etnogeográfica do espaço: questionar como o meio é percebido por aqueles que o habitam, como estes estabelecem um domínio sobre o meio e como concebem suas ordens sociais, suas regras e normas (CLAVAL, 1999). A partir dessas preocupações, o geógrafo poderia, segundo este autor, explorar o universo mental dos homens, de compreendê-los em suas relações com o meio na sua dimensão simbólica e afetiva (CLAVAL, 1999, p. 71). São questões que podem permitir aos geógrafos examinar as 
relações das pessoas com seus ambientes, suas práticas materiais e as sedimentações de suas relações (KATZ, 2009).

Igualmente, a aproximação entre essas disciplinas tem possibilitado aos geógrafos repensar e redefinir as relações entre suas teorias e o campo, promovendo reflexões sobre as implicações políticas e sociais de suas práticas, suas formas de contato com os lugares e comunidades de interesse, assim como suas práticas espaciais, discursivas e corporais in loco (ZUSMAN, 2011). Esse diálogo também tem permitido a valorização de conhecimentos geográficos cotidianos, revelando como a geografia informa o dia-a-dia de grupos sociais, e vice-versa. Nas palavras da geógrafa Perla Zusman:

[...] [O método etnográfico na Geografia] permite priorizar la perspectiva de los informantes por sobre la de los expertos. Hacer "bajar la voz" del investigador puede contribuir a que la investigación ofrezca una perspectiva heterogénea y polifónica de los procesos espaciales analizados. Cabe destacar que esta multiplicación de voces no persigue contrastar la veracidad o falsedad de un proceso o acontecimiento, ya que se concibe que todos los puntos de vista son significativos en la investigación. En realidad, la multiplicación de voces permite desestabilizar representaciones hegemónicas que, muchas veces, no corresponden más que a la mirada de un actor o de un sector social, aunque puede también corresponder a la perspectiva de grupo de un académico. [...] se observa un interés por reflexionar sobre la posición del investigador en el campo, sus condicionantes sociales y políticos, y las relaciones de poder que se establecen entre el investigador y sus informantes ${ }^{4}$ (ZUSMAN, 2011, p. 23).

Tais considerações reforçam uma questão que acreditamos ser central às abordagens geográficas atuais: ao analisar as subjetividades e o trabalho humano na construção dos espaços, faz-se necessário que não se reduza a interpretação destas a simples categorias objetivas de análise do espaço. É preciso uma maior intimidade com os grupos sociais, uma melhor compreensão das geografias vividas em sua diversidade, com seus valores e suas visões de mundo distintas, assim como com uma diversidade de organizações e mobilizações espaciais.

Paul Claval, na conclusão do livro que dedicou à temática, destaca como imperativo o desenvolvimento da análise dessas "geografias concebidas e praticadas por diversos grupos", buscando com estas análises aprofundar o debate sobre as ontologias espaciais, visando

\footnotetext{
${ }^{4}$ Livre tradução: “[...] [O método etnográfico na Geografia] permite priorizar a perspectiva dos informantes sobre a dos especialistas. Fazer "baixar a voz" do investigador pode contribuir que a investigação ofereça uma perspectiva heterogênea e polifônica dos processos especiais analisados. Cabe destacar que essa multiplicação de vozes não persegue contrastar a veracidade ou falsidade de um processo ou acontecimento, já que se concebe que todos os pontos de vista são significativos na investigação. Em realidade, a multiplicação de vozes permite desestabilizar representações hegemônicas que, muitas vezes, não correspondem mais que o olhar de um ator ou de um setor social, ainda que pode também corresponder a perspectiva de grupo de um acadêmico. [...] se observa um interesse por refletir sobre a posição do investigador em campo, seus condicionantes sociais e políticos e as relações de poder que se estabelecem entre o investigador e seus informantes". 
compreender as concepções imaginadas pelos grupos humanos sobre o universo distante e sobre o meio mais próximo. Para tal, destaca duas razões principais ao desenvolvimento da etnogeografia: i) O mundo é moldado pela ação dos homens e se encontra marcado por seus saberes, desejos e aspirações; ii) A geografia não é tão universal quanto normalmente imaginamos (CLAVAL, 1999, p. 70-73). Em suas palavras:

\begin{abstract}
O método etnogeográfico reconstitui primeiramente a percepção que os homens têm do mundo, aprofunda aquilo que pode explorar e pára nos valores que norteiam sua ação. $\mathrm{O}$ espaço que modelam reflete em parte estes dados simples. Mas é preciso preservar-se da ingenuidade. As convicções, os valores e as aspirações habitualmente não se traduzem diretamente no espaço. [...] muitas vezes, os modelos imaginados pelos homens acabam por se traduzirem na realidade de maneira deturpada. O espaço é muito mais modificado pelos princípios que as pessoas respeitam nos seus comportamentos, pelo fundamento que dão à sua sociabilidade, do que pelas crenças e utopias que dizem ter. Grande número de representações são imaginadas para justificar o real, confortar o funcionamento da sociedade, reproduzir suas desigualdades e salvaguardar os privilégios daqueles que a dominam (CLAVAL, 1999, p. 72-73).
\end{abstract}

Tal como destacado por geógrafos de abordagem cultural, além da existência da geografia acadêmica, cada indivíduo apresenta uma geosofia, geografia vernacular ou forma pré-científica de percepção, envolvimento e organização dos espaços. De diferentes formas, uma ampla gama de estudo tem buscado mostrar que comportamentos, práticas concretas, discursos e representações, inclusive científicas, não são puros e sem arestas, pois por trás dos sujeitos, sempre haverá subjetividades, valores, idiossincrasias e histórias particulares que não podem ser controladas inteiramente (MACIEL, 2004, 2006; BERDOULAY, 2012; CLAVAL, 2002; COSGROVE, 2004).

Neste sentido, a consideração da proposta de trabalho de campo etnogeográfico pode ajudar a compreender essas geografias vernaculares e os contextos teórico-metodológicos, mas também políticos e culturais da interação dos geógrafos com esses grupos de interesse. $\mathrm{O}$ campo, mais que momento de confirmação de hipóteses, questões e objetivos, pode ser tomado como etapa de problematização e dúvida acerca dos apontamentos assumidos em etapas anteriores. Problematização desenvolvida via olhar geográfico crítico de observação dos detalhes, em diálogo com a teoria e posicionamentos epistemológicos.

Tal como exposto por Maciel (2004), a importância desse tipo de trabalho de campo surge por seu potencial de ser uma "etapa comunicativa" da pesquisa, de troca entre sujeitos ativos (pesquisadores e moradores do lugar) com a finalidade de levantar dados primários e posteriormente analisa-los de forma interpretativa. Neste sentido, tais questões auxiliam a pensar nossas estratégias metodológicas de entrada em campo, reconhecendo assim que nossa 
imersão, enquanto pesquisadores, em meio aos espaços de investigação, envolvem diversos problemas e que, na tentativa de diminuir tais danos, necessitamos desenvolver estratégias de empatia comunicativa (MACIEL, 2004).

Assim, compreendemos o trabalho de campo como a possibilidade prática, discursiva e representativa da construção de um olhar geográfico menos distanciado sobre a realidade social, política e cultural estudada. Precisamos objetivar em nossas investigações não o pesquisador (nossas características pessoais e idiossincráticas), mas a construção da pesquisa (condições históricas, sociais e políticas do encontro com os pesquisados), atribuindo assim, um valor heurístico ao trabalho de campo, que entrelaça dados e teoria na construção dos resultados da pesquisa (BEAUD e WEBER, 2007; PEIRANO, 2006).

Assim, admitir uma aproximação entre pesquisador, objeto e construção dos dados de pesquisa tornar-se parte de uma estratégia de autorreflexão sobre a impossibilidade, ao menos na abordagem aqui considerada, de fundamentar a pesquisa geográfica no método científico tradicional e sua objetividade científica (BAITZ, 2006). O atual contexto das ciências exige o desenvolvimento de uma pesquisa reflexiva, que submeta constantemente seus dados à reflexão e à crítica (BEAUD E WEBER, 2007), compreendendo o trabalho de campo como um modo de produção do conhecimento, situado entre os lugares, processos e pessoas, cujo pesquisador deve construí-lo a partir de uma auto-reflexividade da natureza parcial de seus trabalhos e das informações coletadas (KATZ, 2009).

Por fim, devemos reconhecer que essa perspectiva teórico-metodológica da pesquisa revela a possibilidade de um engajamento intelectual, psicológico e pessoal do pesquisador em suas práticas de campo, fazendo-se necessário desenvolver uma transformação das formas diretas de relação com a pesquisa (CLAVAL, 2013; SUERTEGARAY, 2002; LACOSTE, 2006; ZUSMAN, 2011). Por isso, nossa compreensão teórico-metodológica da prática de campo aqui se faz na perspectiva de um conhecimento centrado na realidade, cujo método encontra-se em diálogo com nossa concepção particular do mundo (SUERTEGARAY, 2002). Conforme destaca Bitoun (2009) as produções científicas - seus pressupostos teóricometodológicos incluídos - devem ser vistas no movimento das coisas, das ideias e estratégias. A participação dos geógrafos na produção de ferramentas de análise precisa ultrapassar os aspectos instrumentais e se situar em diversas escalas de reflexão, pensando que os resultados adquiridos de nossas operações metodológicas não são exclusivamente reflexos passivos dos fenômenos que pretendem resumir. São, antes de tudo, dados que participam, com outros 
elementos do ambiente informacional onde se estruturam nossos quadros cognitivos, nossa visão do mundo, nossos valores, nossos juízos (BITOUN, 2009, p. 14-15).

\section{CONSIDERAÇÕES FINAIS}

A partir das questões destacadas nesse artigo, buscamos problematizar o que constitui o trabalho de campo para a pesquisa geográfica contemporânea. Conforme destaca Katz (2009), precisamos compreender que o campo "não é simplesmente o que está lá", mas envolve um conjunto de interações culturais, práticas discursivas e espaciais que o marcam como um local de investigação onde o pesquisador faz parte de suas construções.

Apoiado nos aportes teórico-metodológicos fornecidos por abordagens da geografia contemporânea que dialogam com a perspectiva etnográfica do campo, buscamos destacar o trabalho de campo enquanto um recurso central à investigação geográfica, graças ao caráter comunicativo, crítico e situacional dessa prática na história do pensamento geográfico. Igualmente, tentamos destacar a importância de compreender, a partir das experiências vividas no trabalho de campo, o papel das experiências dos lugares e dos territórios na construção dos espaços.

Conforme destaca Claval (2013), reflexões atuais sobre os elementos qualitativos dos estudos geográficos devem reaproximação a ciência (e suas estratégias de campo) de um diálogo com a realidade, compreendendo as espacialidades além da aparência, valorizando uma visão global e compreensiva das paisagens e observando como diferentes práticas sociais contribuem para modelar o espaço, assim como suas atitudes e concepções de vida correlatas.

\section{REFERÊNCIAS}

ALENTEJANO, Paulo R. R.; ROCHA-LEÃO, Otávio M. Trabalho de Campo: Uma ferramenta essencial para os geógrafos ou um instrumento banalizado? In: Boletim Paulista de Geografia. São Paulo: Número 84, jul. 2006, p. 51-68.

ALMEIDA, Maria Geralda. Uma Leitura Etnogeográfica do Brasil Sertanejo. In: SERPA, Angelo. (Org.). Espaços Culturais: vivências, imaginações e representações. Salvador: Edufba, 2008, p. 313-336.

BAITZ, Ricardo. A Implicação: Um novo sedimento a se explorar na Geografia? In: Boletim Paulista de Geografia. São Paulo: Número 84, jul. 2006, p. 25-59.

BEAUD, Stéphane; WEBER, Florence. Guia para a pesquisa de campo: Produzir e analisar dados etnográficos. Petrópolis: Vozes, 2007. 
BERDOULAY, Vincent. Espaço e Cultura. In: CASTRO, Iná Elias de; GOMES, Paulo César da Costa; CORRÊA, Roberto Lobato (Org.). Olhares Geográficos. Rio de Janeiro: Bertrand Brasil, 2012, p. 101-131.

BERQUE, Augustin. Paisagem-marca, paisagem-matriz: Elementos da problemática para uma geografia cultural. In: CORRÊA, Roberto Lobato; ROSENDAHL, Zeny (Org.). Geografia Cultural: Uma antologia (Volume 1). Rio de Janeiro: EdUERJ, 2012, p. 239-243. BITOUN, Jan. A produção de Atlas intra-urbanos de desenvolvimento humano no Brasil: Desafios, limites e contribuições ao estudo da desigualdade sócio-espacial e à divulgação da informação geográfica - o caso do Recife. In: $12^{\circ}$ Encontro de Geógrafos da América Latina. Anais... Montevidéu, 2009, 15p.

CLAVAL, Paul. Etnogeografias - Conclusão. Espaço e Cultura: Rio de Janeiro, ${ }^{\circ}$ 07, jan./jun. de 1999, p. 69-74. Disponível em: <http://www.e-publicacoes.uerj.br/index.php/espa coecultura/article/view/6995/4944>. Acesso em: 21 out. 2015.

"A Volta do Cultural" na Geografia. In: Revista Mercator, Fortaleza, Ano 01, número 01, jan/jun de 2002, p. 19-28. Disponível em: <http://www.mercator.ufc.br/index.php /mercator/article/view/192/158>. Acesso em: 13 dez. 2012.

Le Rôle du Terrain en Géographie: Des épistémologies de la curiosité à celles du desir. Confins, 17, 2013. Disponível em: <http://confins.revues.org/8373>. Acesso em: 23 out. 2015.

COSGROVE, Denis. A Geografia está em toda parte: Cultura e simbolismo nas paisagens humanas. In: CORRÊA, Roberto Lobato; ROSENDAHL, Zeny. (Org.). Paisagem, Tempo e Cultura. Rio de Janeiro: EdUERJ, 2004, p. 92-123.

DO RIO, Gisela Aquino Pires. Trabalho de Campo na (Re)Construção da Pesquisa Geográfica: Reflexões sobre um tradicional instrumento de investigação. GEOgraphia (UFF), v. 13, p. 42-56, 2011. Disponível em: < http://www.uff.br/geographia/ojs/index.php/ geographia/article/view/404>. Acesso em: 13 jun. 2016.

HERBERT, Steve. For Ethnography. Progress in Human Geography. 2000, nº 24,4, p. 550 568. Disponível em: <http://www.gla.ac.uk/0t4/crcees/files/summerschool/readings/summer school09/readings/Herbert_For_Ethnography.pdf>. Acesso em: 02 jul. 2016.

HOEFLE, Scott William. Antropologia e Geografia: Convergências e divergências históricas. Espaço e Cultura (UERJ), Rio de Janeiro: no 22, jan./dez. 2007, p. 04-31. Disponível em: <http://www.e-publicacoes.uerj.br/index.php/espacoecultura/article/viewFile/3509/2436>. Acesso em: 02 jul. 2016. 
Revista de Geografia (Recife) V. 36, No. 2, 2019 - ISSN: 2238-6211

KATZ, Cindy. Fieldwork. In: GREGORY, Derek; JOHNSTON, Ron; PRATT, Geraldine; WATTS, Michael J.; WHATMORE, Sarah (Edit). The Dictionary of Human Geography. $5^{\circ}$ ed. Londres: 2009, Wiley-Blackwell, p. 251-252.

LACOSTE, Yves. A Pesquisa e o Trabalho de Campo: Um problema político para os pesquisadores, estudantes e cidadãos. In: Boletim Paulista de Geografia. São Paulo: Número 84, jul. 2006, p. 77-92.

MACIEL, Caio Augusto Amorim. Metonímias Geográficas: Imaginação e Retórica da paisagem no semi-árido pernambucano. 2004. Tese (Doutorado em Geografia) Universidade Federal do Rio de Janeiro. Rio de janeiro, 2004.

Interpretando a cognição ambiental na comunidade rural de Sítio dos Montes, Belém do São Francisco - PE: Premissas para ações de educação ambiental com pequenos agricultores do semi-árido nordestino. Portal do São Francisco (CESVASF), vol. V, 2006, p. 01-20.

PATERSON, Mark. Haptic Geographies: Ethnography, haptic knowledges and sensous dispositions. Progress in Human Geography. 2009, no 33(6), p. 766-788. Disponível em: < http://phg.sagepub.com/content/33/6/766.short>. Acesso em 02 jul. 2016.

PEIRANO, Mariza. A Teoria Vivida e outros ensaios de Antropologia. Rio de Janeiro: Jorge Zahar Ed., 2006.

PULMAN, Bertrand. Por uma história da noção de campo. Cadernos de Campo: São Paulo, $\mathrm{n}^{\circ}$ 16, 2007, p. 221-232. Disponível em: <http://www.revistas.usp.br/cadernosdecampo/article /viewFile/50066/54193>. Acesso em: 21 out. 2015.

SUERTEGARAY, Dirce Maria Antunes. Pesquisa de campo em geografia. GEOgraphia. Vol. 04, no 07, 2002, p. 64-68. Disponível em: <http://www.uff.br/geographia/ojs/index.php/geog raphia/article/view/78/76>. Acesso em: 03 jun. 2015.

TRICART, Jean. O campo na dialética da geografia. Revista do Departamento de Geografia - USP, Vol. 19, 2006, p. 104-110. Disponível em: <http://www.revistas.usp.br/ rdg/article/view/47256/50992>. Acesso em: 09 abr. 2015.

VENTURI, Luis Antonio Bittar. O papel da técnica no processo de produção científica. In: Boletim Paulista de Geografia. São Paulo: Número 84, jul. 2006, p. 69-76.

ZUSMAN, Perla. La Tradición del trabajo de campo en Geografía. Geograficando, 2011, 7(7), p. 15-32. Disponível em: <http://www.memoria.fahce.unlp.edu.ar/art_revistas/pr.5089/ pr.5089.pdf>. Acesso em: 02 jul. 2016. 